\title{
Forecasting the progress towards the target of Millennium Development Goal 1C in children under 5 years of age in Bangladesh
}

\author{
Md Tanvir Hasan 1,*, Ricardo J Soares Magalhaes ${ }^{2,3,4}$, Gail M Williams ${ }^{1}$ and \\ Abdullah A Mamun ${ }^{1}$ \\ 'School of Population Health, University of Queensland, Level 2, Public Health Building, Herston Road, Herston, QLD \\ 4006, Australia: ${ }^{2}$ Infectious Disease Epidemiology Unit, School of Population Health, University of Queensland, \\ Herston, Queensland, Australia: ${ }^{3}$ School of Veterinary Science, University of Queensland, Gatton Campus, Gatton, \\ Queensland, Australia: ${ }^{4} \mathrm{WHO}$ Collaborating Centre for Children's Health and Environment, Queensland Children's \\ Medical Research Institute, University of Queensland, Herston, Queensland, Australia
}

Submitted 21 January 2014: Final revision received 23 September 2014: Accepted 11 December 2014: First published online 4 February 2015

\begin{abstract}
Objective: To estimate the average annual rates of reduction of stunting, underweight and wasting for the period 1996 to 2011, and to evaluate whether Bangladesh will be expected to achieve the target of Millennium Development Goal 1C of reducing the prevalence of underweight by half by 2015 .

Design: We used five nationwide, cross-sectional, Demographic and Health Survey data sets to estimate prevalence of undernutrition defined by stunting, underweight and wasting among children under 5 years of age using the WHO child growth standards. We then computed the average annual rates of reduction of prevalence of undernutrition using the formula derived by UNICEF. Finally, we projected the prevalence of undernutrition for the year 2015 using the estimated average annual rates of reduction.

Setting: Nationwide covering Bangladesh.

Subjects: Children under 5 years of age ( $n 28$ 941).

Results: The prevalence of stunting decreased by $18.8 \%$ (from $60.0 \%$ to $41.2 \%$ ), underweight by $16 \cdot 0 \%$ (from $52 \cdot 2 \%$ to $36 \cdot 2 \%$ ) and wasting by $5 \cdot 1 \%$ (from $20.6 \%$ to $15.5 \%$ ) during 1996 to 2011 . The overall average annual rates of reduction were $2 \cdot 84 \%, 2.69 \%$ and $2.47 \%$, respectively, for stunting, underweight and wasting. We forecast that in 2015 , the prevalence of stunting, underweight and wasting will be $36.7 \%, 32.5 \%$ and $14.0 \%$, respectively, at the national level. The prevalence of undernutrition is likely to remain high in rural areas, in the Sylhet division and in the poorest wealth quintile.

Conclusions: Bangladesh is likely to achieve the Millennium Development Goal $1 \mathrm{C}$ target of reducing the prevalence of underweight by half by 2015 . However, it is falling behind in reducing stunting and further investment is needed to reduce individual, household and environmental determinants of stunting in Bangladesh.
\end{abstract}

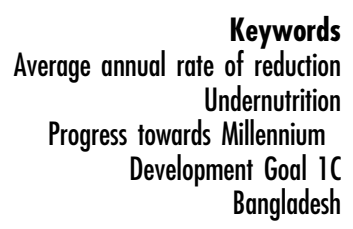

Childhood undernutrition including stunting, underweight and wasting is highly prevalent in developing countries and is the underlying cause of $35 \%$ of all deaths among children under 5 years of age (under- $5 \mathrm{~s})^{(1)}$. More than a quarter of all children in developing countries are either underweight or stunted. Countries in South Asia including Bangladesh have the highest prevalence and largest number of malnourished children worldwide ${ }^{(2)}$. Although the prevalence of undernutrition among under- $5 \mathrm{~s}$ has declined considerably over the past three decades, recent data in Bangladesh show that $16 \%$ of under- 5 s suffer from wasting, $41 \%$ suffer from stunting and $36 \%$ are underweight $^{(3)}$. Moreover, a recent report ranked Bangladesh as number sixth in terms of the total number of stunted children and number fifth in terms of the total number of wasted $_{\text {children }}^{(4)}$. Despite considerable efforts made by the Government of Bangladesh and other local and international nutrition agencies working there to improve child nutrition, undernutrition remains a major public health problem.

Undernutrition in children is a multifactorial condition in that sociodemographic, cultural and environmental factors 
can greatly influence children's nutritional status. A number of studies have documented parental education, maternal nutritional status, maternal employment status, exposure to mass media, household socio-economic status, community environment, the number of under- $5 \mathrm{~s}$ in the family, size of the baby at birth, birth order and area of residence as important determinants of child undernutrition in Bangladesh ${ }^{(5-9)}$. Studies have consistently reported that children residing in rural areas, belonging to poorer household and whose parents have less formal education are at higher risk of undernutrition ${ }^{(3,9,10)}$.

While previous studies have documented well the determinants of undernutrition, only a few have looked at the temporal pattern of undernutrition prevalence in a country. A trend analysis, using data collected for the time period 1990-2005 through the Nutritional Surveillance Project based in rural areas and urban slums in large cities of Bangladesh, found considerable differences in rates of decline of undernutrition prevalence across regions and across socio-economic groups ${ }^{(11)}$. Das et al. ${ }^{(12)}$ reported considerable differences in the rates of decline of undernutrition prevalence across residence, region, age of child and mother's education using nationally representative data from six surveys conducted during the period 1985 to 2004. Both studies provided evidence that the prevalence of undernutrition is decreasing in particular areas and populations of Bangladesh. However, neither study forecasted the nationwide trend of decrease to ascertain whether Bangladesh is on track to achieve the Millennium Development Goal 1C (MDG1C) target of halving the prevalence of underweight among under-5s by $2015^{(13)}$.

Recent studies conducted in Bangladesh have reported contradictory statements about whether the country will be able to achieve the MDG1C target. While Ahmed et $a l .{ }^{(14)}$ argued that if the current rate of reduction continues the country is unlikely to achieve the target, the most recent Bangladesh Demographic and Health Survey 2011 (BDHS 2011) report ${ }^{(3)}$ states that at the current rate of reduction the target can be achieved. Both studies draw their conclusions based on observed prevalences found in previous BDHS. Moreover, neither study estimated the average annual rate of reduction (AARR) commonly used to track the progress of countries towards achieving the MDG1C of halving the prevalence of underweight in under- 5 s by $2015^{(15)}$. For a country like Bangladesh, where more than one-third of children are still underweight ${ }^{(3,15)}$, estimates of the AARR are needed to track MDG1C progress and to set up future goals for reducing the prevalence of underweight. It is also important to examine the AARR for the other two undernutrition indicators, stunting and wasting, since they represent different dimensions of undernutrition; namely chronic undernutrition and acute undernutrition, respectively ${ }^{(16)}$.

Bangladesh has a wealth of nationally representative cross-sectional data that are underutilized. In the present study, we aimed to examine whether the reduction of prevalence of undernutrition occurred at a similar rate across socio-economic groups and rural/urban households using the five most recent, nationwide, cross-sectional BDHS data sets from 1996 to 2011. The objective was to estimate the AARR for the three common indicators of undernutrition (stunting, underweight and wasting) and to forecast the prevalence of stunting, underweight and wasting for the year 2015 by selected background characteristics of children, such as gender, area of residence, wealth quintile, maternal education and maternal nutritional status.

\section{Methods}

\section{Demographic and Health Surveys}

We used nationally representative BDHS data sets to examine trends in undernutrition among under- $5 \mathrm{~s}$ from 1996-1997 to 2011. To date, six Demographic and Health Surveys (DHS) have been conducted in Bangladesh: in 1993-1994, 1996-1997, 1999-2000, 2004, 2007 and 2011. Anthropometric data of children are available for all BDHS except that conducted in 1993-1994. Our study population included 29930 surviving children whose height and weight were measured in the five surveys conducted between 1996 and 2011. There were 264 (0.88\%) children whose height or age was out of plausible limits and 725 children $(2.42 \%)$ had either height or weight out of plausible limits. The final sample included 28941 children for whom complete anthropometric data were available.

The DHS are cross-sectional and use a two-stage stratified sampling design with stratification done by urban and rural areas within each division of the country ${ }^{(3)}$. At the first stage, primary sampling units defined as census enumeration areas are selected and at the second stage households are randomly selected from these primary sampling units. Within selected households, ever-married women aged 15-49 years are interviewed. Women are asked questions about a range of topics, such as background characteristics (e.g. height, age, education, media exposure, employment, etc.), reproductive history, use and source of family planning method, antenatal and postnatal history, breast-feeding and infant feeding practices, child immunization and child illness, marriage, fertility preferences, husband's background, awareness of AIDS and other sexually transmitted diseases, knowledge of tuberculosis and domestic violence. The DHS questionnaires and sampling scheme are almost identical at each time point, enabling comparison of indicators over time.

\section{Statistical analysis}

We defined undernutrition using three indices: height/ length-for-age, weight-for-height/length and weight-forage. A child was categorized as stunted if his/her height/ length-for-age was more than -2 SD below the median height/length-for-age of the WHO reference population 
(height/length-for-age $Z$-score $(\mathrm{HAZ})<-2$ ). A child was categorized as underweight or wasted if his/her weightfor-age or weight-for-height/length was more than $-2 \mathrm{SD}$ below the median weight-for-age or weight-for-height/ length of the WHO reference population, respectively (weight-for-age $Z$-score (WAZ) $<-2$ or weight-for-height/ length $Z$-score (WHZ) $<-2$, respectively) ${ }^{(17)}$. The prevalence of stunting, underweight and wasting was estimated using the WHO 2006 child growth standards ${ }^{(18)}$. This allowed us to compare estimates across survey years. We used line charts to summarize overall trends in prevalence of undernutrition. To examine differences in rates of decline by background characteristics of children, we utilized six variables. These were: sex of the child, maternal education, maternal nutritional status, area of residence, division and household wealth quintile. Maternal education was divided into three categories: no formal education, primary education and secondary education or higher. Maternal nutritional status was measured using BMI categorized into three groups: underweight (BMI $\left.<18.5 \mathrm{~kg} / \mathrm{m}^{2}\right)$, normal weight $\left(18.5 \leq \mathrm{BMI}<25.0 \mathrm{~kg} / \mathrm{m}^{2}\right)$ and overweight $\left(\mathrm{BMI} \geq 25.0 \mathrm{~kg} / \mathrm{m}^{2}\right)^{(19)}$. We excluded information of 1763 mothers who were pregnant at the time of the surveys or whose height or weight was out of plausible limits or missing. Finally, household wealth index was classed into quintiles: poorest, poor, middle, rich and richest. All prevalence estimates are calculated based on the DHS design.

We calculated and compared AARR of prevalence of undernutrition assuming the change of prevalence as an exponential function. This approach has been used by UNICEF to monitor global trends in prevalence of underweight $^{(15)}$. The methodological details of calculating AARR have been described in a technical note by $\mathrm{UNICEF}^{(20)}$. If the prevalence $Y_{t}$ is known for any given year $t$ and the annual rate of reduction is $b \%$, then the prevalence $Y_{t+n}$ for any later year $t+n$ can be calculated as:

$$
Y_{t+n}=Y_{t}(1-b \%)^{n} \text {. }
$$

We used the median date of fieldwork as the standard time point to calculate the time between surveys. For example, 15 January 1997 was the median date of fieldwork for the first DHS round (BDHS 1996-1997) and 31 January 2000 was the median date for the second DHS round (BDHS 1999-2000). The duration between the two surveys was therefore calculated as 3.04 years. Gaps were calculated for all surveys and used to estimate AARR of prevalence of undernutrition for different time periods. To obtain the overall AARR for the period 1996 and 2011 we first estimated $\ln (1-b \%)$ for different time periods; then we took the arithmetic mean of these $\ln (1-b \%)$ values and finally back-transformed the mean to $b \%$. This overall ARRR was later used to project the prevalence of undernutrition for the year 2015. For the projection, $Y_{t}$ in equation (1) was considered the baseline prevalence in 2011 and $Y_{t+n}$ the projected prevalence in 2015. The overall AARR was assumed to be constant for the period 2011 to 2015 .

\section{Results}

\section{General trends in prevalence of undernutrition}

Table 1 shows the descriptive statistics for age, height, weight, HAZ, WAZ and WHZ of the 28941 children used in the analysis. The mean height and weight of children were $81.6 \mathrm{~cm}$ and $10 \cdot 1 \mathrm{~kg}$, respectively. The trends suggest that mean height and weight of children have increased consistently since 1996. The mean HAZ increased from -2.3 in 1996-1997 to -1.7 in 2011, whereas the mean WAZ increased from -2.0 in 1996-1997 to -1.6 in 2011.

Figure 1 shows the general trends in prevalence of stunting, underweight and wasting among under-5s. It is clear that the prevalence of stunting has been decreasing steadily in the past 15 years. However, the prevalence of underweight and wasting did not follow a particular pattern. Overall, the prevalence of stunting declined from $60.0 \%$ in $1996-1997$ to $41.2 \%$ in 2011 , and was stable in the 1999-2000 and 2004 surveys. On the other hand, the prevalence of underweight declined from $52.2 \%$ in $1996-1997$ to $36 \cdot 2 \%$ in 2011 but was stable between 1999-2000 and 2007. Overall, the highest decrease in prevalence of undernutrition occurred during the period from 1996-1997 to 1999-2000.

Table 1 Age, weight, height and anthropometric indicators (means and standard deviations) of children under 5 years of age (n 28 941): Bangladesh Demographic and Health Surveys (BDHS) 1996-1997, 1999-2000, 2004, 2007 and 2011

\begin{tabular}{|c|c|c|c|c|c|c|c|c|c|c|c|}
\hline & \multicolumn{2}{|c|}{$\begin{array}{c}\text { BDHS 1996-1997 } \\
(n \text { 4706) }\end{array}$} & \multicolumn{2}{|c|}{$\begin{array}{c}\text { BDHS 1999-2000 } \\
(n \text { 5351) }\end{array}$} & \multicolumn{2}{|c|}{$\begin{array}{l}\text { BDHS 2004 } \\
(n \text { 5937) }\end{array}$} & \multicolumn{2}{|c|}{$\begin{array}{l}\text { BDHS 2007 } \\
(n 5300)\end{array}$} & \multicolumn{2}{|c|}{$\begin{array}{l}\text { BDHS } 2011 \\
(n 7647)\end{array}$} & \multirow[b]{2}{*}{ Overall mear } \\
\hline & Mean & SD & Mean & SD & Mean & SD & Mean & SD & Mean & SD & \\
\hline Age of child (months) & $29 \cdot 2$ & $17 \cdot 3$ & 28.5 & $17 \cdot 5$ & $29 \cdot 3$ & $17 \cdot 1$ & $29 \cdot 6$ & $17 \cdot 1$ & $30 \cdot 4$ & $17 \cdot 4$ & $29 \cdot 4$ \\
\hline Weight of child (kg) & $9 \cdot 7$ & 3.0 & 9.9 & $3 \cdot 1$ & $10 \cdot 0$ & 3.0 & $10 \cdot 1$ & $3 \cdot 0$ & $10 \cdot 4$ & $3 \cdot 1$ & $10 \cdot 1$ \\
\hline Height of child $(\mathrm{cm})$ & 79.9 & $12 \cdot 8$ & 80.5 & $13 \cdot 6$ & 81.4 & $13 \cdot 1$ & $82 \cdot 3$ & $13 \cdot 0$ & $83 \cdot 2$ & $13 \cdot 6$ & 81.6 \\
\hline HAZZ & $-2 \cdot 3$ & 1.5 & $-2 \cdot 0$ & 1.4 & $-2 \cdot 0$ & 1.4 & $-1 \cdot 7$ & 1.3 & $-1 \cdot 7$ & 1.4 & -1.9 \\
\hline WAZ & $-2 \cdot 0$ & 1.2 & $-1 \cdot 8$ & $1 \cdot 1$ & $-1 \cdot 8$ & 1.1 & $-1 \cdot 7$ & $1 \cdot 1$ & $-1 \cdot 6$ & 1.2 & $-1 \cdot 8$ \\
\hline WHZ & $-1 \cdot 0$ & $1 \cdot 3$ & -0.9 & $1 \cdot 1$ & -0.9 & $1 \cdot 1$ & $-1 \cdot 0$ & $1 \cdot 1$ & -0.9 & $1 \cdot 2$ & -0.9 \\
\hline
\end{tabular}

HAZ, height/length-for-age Z-score; WAZ, weight-for-age Z-score; WHZ, weight-for-height/length Z-score. 


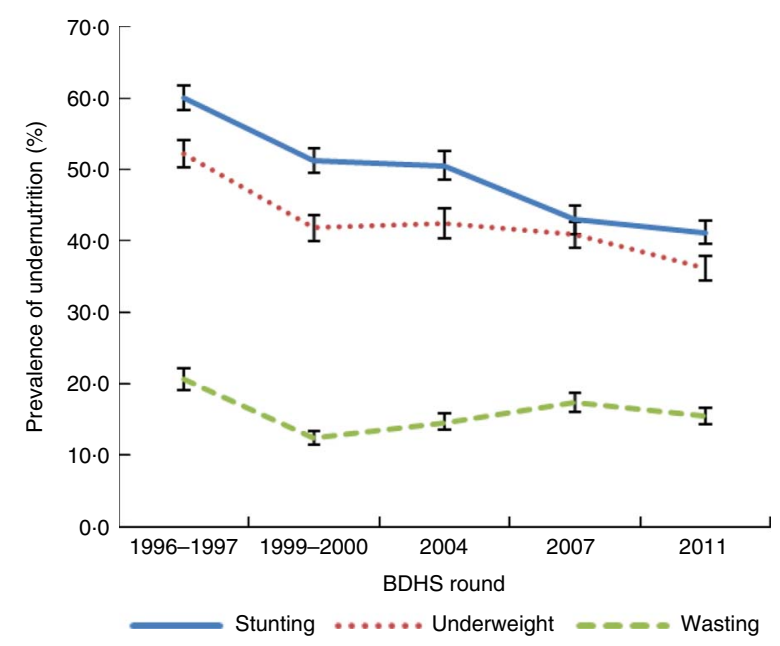

Fig. 1 (colour online) Trends in weighted prevalence of undernutrition (stunting, underweight and wasting) among children under 5 years of age $(n$ 28941) at national level: Bangladesh Demographic and Health Surveys (BDHS) 19961997, 1999-2000, 2004, 2007 and 2011. Values are means with their $95 \%$ confidence interval represented by vertical bars

\section{Trends in prevalence of undernutrition by selected background characteristics of children}

Table 2 shows the trends in prevalence of stunting, underweight and wasting according to selected background characteristics of the children. The prevalence was higher among children living in rural areas and among children belonging to poor households in all surveys. The prevalence of stunting was higher among male children compared with female children, but the prevalence of underweight was higher among female children than male children, in four of the five surveys. In all surveys, the prevalence of stunting was higher among children belonging to poor households. Children of underweight mothers (BMI $<18.5 \mathrm{~kg} / \mathrm{m}^{2}$ ) were more likely to be stunted, underweight and wasted in all the surveys compared with their counterparts.

\section{Average annual rates of reduction of undernutrition prevalence by selected background characteristics of children}

Table 3 shows the estimated AARR of prevalence of undernutrition for the past 15 years. It shows that the overall national AARR for the period 1996 to 2011 were $2.84 \%, 2.69 \%$ and $2.47 \%$, respectively, for stunting, underweight and wasting. The overall AARR for stunting, underweight and wasting were higher for male children, for children living in rural areas and children belonging to richer households. The overall ARRR of stunting was higher for Rajshahi division and the overall AARR of underweight was higher for Khulna division.

\section{Projected prevalence of undernutrition for 2015}

Table 4 shows the projected prevalence of stunting, underweight and wasting for 2015 by selected background characteristics of the children. It shows that if the overall AARR continue, a further minor improvement in reduction of malnutrition is likely. The prevalence of underweight is predicted to be $32.5 \%$, while the prevalences of stunting and wasting are predicted to be $36.7 \%$ and $14.0 \%$, respectively, in 2015 at the national level. Future prevalence rates are expected to vary across geographic regions and socio-economic groups. The prevalences of stunting, underweight and wasting are forecasted to remain high in rural areas, in Sylhet division and in the poorest wealth quintile.

\section{Discussion}

The results of the present study indicate that undernutrition in under-5s has improved from 1996 to 2011 in Bangladesh. However, the mean HAZ and WAZ $(-1.7$ and $-1 \cdot 6$, respectively, in 2011 and $-2 \cdot 3$ and $-2 \cdot 0$, respectively, in 1996) remain low compared with other developing countries. A recent systematic analysis of populationbased studies in 141 developing countries reported mean HAZ and WAZ as $-1 \cdot 16$ and $-0 \cdot 84$, respectively, among under- $5 s^{(21)}$.

Our estimates suggest that the prevalence of stunting decreased by $18.8 \%$ (from $60.0 \%$ to $41.2 \%$ ), underweight by $16.0 \%$ (from $52.2 \%$ to $36.2 \%$ ) and wasting by $5.1 \%$ (from $20 \cdot 6 \%$ to $15 \cdot 5 \%$ ) during the period 1996 to 2011. The reduction in prevalence of stunting was somewhat higher compared with that for prevalence of underweight. However, we noted that the prevalence of stunting is still very high, $41.2 \%$ at the national level in 2011. Recent studies have indicated that stunting is a better indicator of nutritional deficiencies than underweight ${ }^{(15,22,23)}$ and Bangladesh has a very high prevalence of stunting ${ }^{(4)}$. This indicates the need for urgent action to address this issue.

The overall AARR results suggest that the prevalence of stunting and underweight decreased faster (2.84\% per year and $2.69 \%$ per year, respectively) than the prevalence of wasting $(2.47 \%$ per year) during the period 1996 to 2011. The AARR of all three indicators of undernutrition (stunting, underweight and wasting) was much greater during the period 1996 to 2000 compared with other periods. For example, the AARR for stunting was $5.08 \%$ per year during 1996 to 2000 compared with $0.33 \%$ per year during the period 2000 to 2004 . While we were not able to ascertain the determinants of this difference, studies have indicated that the sharp decline in the prevalence of undernutrition in the late 1990s may have been associated with improvement in maternal education and wealth, reduction in fertility, measles immunization and rural electrification ${ }^{(14,24)}$.

Our estimate of the AARR for the prevalence of underweight (2.69\% per year) differs from that put forward by UNICEF, which reported an AARR of $2.3 \%$ per year for 
Table 2 Trends in weighted prevalence of stunting, underweight and wasting by selected background characteristics of children under 5 years of age ( $n 28941$ ): Bangladesh Demographic and Health Surveys (BDHS) 1996-1997, 1999-2000, 2004, 2007 and 2011

\begin{tabular}{|c|c|c|c|c|c|c|c|c|c|c|c|c|c|c|c|}
\hline & \multicolumn{3}{|c|}{ BDHS 1996-1997 ( $n$ 4706) } & \multicolumn{3}{|c|}{ BDHS 1999-2000 ( $n$ 5351) } & \multicolumn{3}{|c|}{ BDHS 2004 ( $n$ 5937) } & \multicolumn{3}{|c|}{ BDHS 2007 (n 5300) } & \multicolumn{3}{|c|}{ BDHS 2011 ( $n$ 7647) } \\
\hline & $\begin{array}{l}\text { Stunting } \\
(\%)\end{array}$ & $\begin{array}{c}\text { Underweight } \\
(\%)\end{array}$ & $\begin{array}{l}\text { Wasting } \\
(\%)\end{array}$ & $\begin{array}{c}\text { Stunting } \\
(\%)\end{array}$ & $\begin{array}{c}\text { Underweight } \\
(\%)\end{array}$ & $\begin{array}{c}\text { Wasting } \\
(\%)\end{array}$ & $\begin{array}{c}\text { Stunting } \\
(\%)\end{array}$ & $\begin{array}{c}\text { Underweight } \\
(\%)\end{array}$ & $\begin{array}{c}\text { Wasting } \\
(\%)\end{array}$ & $\begin{array}{l}\text { Stunting } \\
(\%)\end{array}$ & $\begin{array}{c}\text { Underweight } \\
(\%)\end{array}$ & $\begin{array}{c}\text { Wasting } \\
(\%)\end{array}$ & $\begin{array}{c}\text { Stunting } \\
(\%)\end{array}$ & $\begin{array}{c}\text { Underweight } \\
(\%)\end{array}$ & $\begin{array}{c}\text { Wasting } \\
(\%)\end{array}$ \\
\hline \multicolumn{16}{|l|}{ Sex of child } \\
\hline Female & $59 \cdot 6$ & $52 \cdot 9$ & $19 \cdot 2$ & $50 \cdot 9$ & $42 \cdot 9$ & 11.5 & $49 \cdot 7$ & $42 \cdot 3$ & $13 \cdot 4$ & $42 \cdot 4$ & $42 \cdot 1$ & $16 \cdot 6$ & $42 \cdot 0$ & $38 \cdot 3$ & $15 \cdot 1$ \\
\hline Male & 60.5 & 51.5 & $22 \cdot 0$ & 51.5 & $40 \cdot 7$ & $13 \cdot 1$ & 51.4 & $42 \cdot 6$ & $15 \cdot 7$ & 43.6 & 39.6 & $18 \cdot 2$ & 40.4 & 34.2 & $15 \cdot 9$ \\
\hline \multicolumn{16}{|l|}{ Maternal education } \\
\hline No education & $66 \cdot 0$ & 58.5 & $22 \cdot 8$ & $58 \cdot 8$ & 49.5 & $14 \cdot 6$ & 58.9 & $50 \cdot 7$ & $16 \cdot 5$ & $51 \cdot 3$ & $46 \cdot 9$ & $19 \cdot 3$ & $51 \cdot 0$ & 48.8 & $17 \cdot 8$ \\
\hline Primary & $61 \cdot 0$ & $50 \cdot 3$ & $17 \cdot 8$ & $52 \cdot 9$ & 41.9 & $11 \cdot 3$ & $53 \cdot 2$ & $43 \cdot 1$ & $14 \cdot 3$ & $48 \cdot 7$ & $46 \cdot 4$ & $19 \cdot 0$ & $46 \cdot 9$ & $42 \cdot 2$ & $18 \cdot 0$ \\
\hline Secondary or higher & 38.5 & $34 \cdot 3$ & $17 \cdot 9$ & 34.6 & $27 \cdot 1$ & $9 \cdot 2$ & 37.8 & 31.9 & 12.5 & 33.2 & $32 \cdot 7$ & 14.8 & $33 \cdot 6$ & $27 \cdot 3$ & $13 \cdot 0$ \\
\hline \multicolumn{16}{|l|}{ Maternal BMI $\left(\mathrm{kg} / \mathrm{m}^{2}\right)$} \\
\hline Underweight (BMI $\leq 18.5)$ & $63 \cdot 3$ & $58 \cdot 8$ & 24.9 & 55.5 & $50 \cdot 1$ & $16 \cdot 4$ & $57 \cdot 7$ & $52 \cdot 9$ & $19 \cdot 8$ & $48 \cdot 3$ & $51 \cdot 1$ & 23.5 & 51.0 & $49 \cdot 7$ & 20.6 \\
\hline Normal $(18.5 \leq \mathrm{BMI}<25.0)$ & $56 \cdot 5$ & $44 \cdot 2$ & $15 \cdot 8$ & 47.6 & $35 \cdot 1$ & 9.4 & $47 \cdot 1$ & $37 \cdot 1$ & 11.9 & 41.5 & 37.4 & 15.4 & 38.9 & $32 \cdot 4$ & $14 \cdot 1$ \\
\hline Overweight $(\overline{\mathrm{BMI}} \geq 25 \cdot 0)$ & $36 \cdot 3$ & 35.9 & $16 \cdot 8$ & $26 \cdot 2$ & 19.5 & 5.9 & $25 \cdot 1$ & $16 \cdot 2$ & 7.4 & 21.4 & $15 \cdot 5$ & $7 \cdot 0$ & $25 \cdot 2$ & $19 \cdot 8$ & 8.8 \\
\hline \multicolumn{16}{|l|}{ Residence } \\
\hline Urban & $45 \cdot 6$ & 38.8 & 15.5 & 41.9 & 34.4 & $10 \cdot 9$ & 44.5 & $37 \cdot 3$ & $13 \cdot 6$ & $36 \cdot 4$ & $33 \cdot 3$ & 14.4 & $36 \cdot 4$ & $27 \cdot 8$ & $13 \cdot 8$ \\
\hline Rural & 61.5 & 53.6 & $21 \cdot 1$ & 53.0 & $43 \cdot 2$ & $12 \cdot 6$ & $52 \cdot 0$ & 43.7 & 14.8 & 44.7 & $42 \cdot 9$ & $18 \cdot 2$ & 42.5 & 38.5 & $16 \cdot 0$ \\
\hline \multicolumn{16}{|l|}{ Division } \\
\hline Barisal & $67 \cdot 0$ & 53.8 & $16 \cdot 9$ & $52 \cdot 6$ & 44.9 & $12 \cdot 8$ & $55 \cdot 8$ & 40.5 & $9 \cdot 3$ & $47 \cdot 3$ & $45 \cdot 7$ & $18 \cdot 1$ & 44.4 & $39 \cdot 3$ & $14 \cdot 7$ \\
\hline Chittagong & 59.9 & $55 \cdot 2$ & 24.7 & $52 \cdot 4$ & $42 \cdot 1$ & $12 \cdot 2$ & $52 \cdot 8$ & $45 \cdot 4$ & $15 \cdot 7$ & $45 \cdot 2$ & 41.3 & $17 \cdot 6$ & $41 \cdot 1$ & $37 \cdot 2$ & $15 \cdot 7$ \\
\hline Dhaka & $60 \cdot 7$ & 50.5 & $18 \cdot 2$ & $51 \cdot 3$ & $40 \cdot 4$ & $11 \cdot 7$ & $52 \cdot 6$ & $42 \cdot 0$ & $12 \cdot 9$ & 43.8 & 39.8 & $15 \cdot 4$ & 43.4 & $36 \cdot 3$ & $15 \cdot 5$ \\
\hline Khulna & 53.8 & $46 \cdot 2$ & $21 \cdot 1$ & $45 \cdot 1$ & $34 \cdot 1$ & $10 \cdot 9$ & $40 \cdot 3$ & $35 \cdot 0$ & $16 \cdot 3$ & 34.9 & 34.3 & $18 \cdot 8$ & 33.6 & 28.8 & $14 \cdot 7$ \\
\hline Rajshahi & $58 \cdot 3$ & $52 \cdot 0$ & $19 \cdot 8$ & $49 \cdot 0$ & $43 \cdot 3$ & 13.6 & 47.9 & $42 \cdot 7$ & $16 \cdot 2$ & 41.5 & $43 \cdot 1$ & 18.9 & 33.7 & 34.1 & $16 \cdot 4$ \\
\hline Sylhet & $65 \cdot 3$ & $57 \cdot 8$ & $22 \cdot 4$ & $61 \cdot 0$ & $50 \cdot 1$ & $13 \cdot 2$ & 53.5 & $46 \cdot 7$ & $15 \cdot 1$ & 43.9 & 41.6 & $18 \cdot 1$ & $49 \cdot 8$ & $45 \cdot 0$ & 18.4 \\
\hline & & & & & & & & & & & & & $42 \cdot 7$ & 34.0 & $13 \cdot 1$ \\
\hline \multicolumn{16}{|l|}{ Wealth quintile } \\
\hline Poorest & $65 \cdot 0$ & 59.7 & 23.8 & $61 \cdot 6$ & 53.8 & $16 \cdot 0$ & $62 \cdot 1$ & $55 \cdot 7$ & $17 \cdot 8$ & 53.8 & $50 \cdot 3$ & $20 \cdot 6$ & 53.5 & $50 \cdot 3$ & $17 \cdot 8$ \\
\hline Poor & 68.5 & 59.1 & 21.4 & $56 \cdot 6$ & $45 \cdot 0$ & 13.7 & 55.2 & $46 \cdot 8$ & $15 \cdot 2$ & $50 \cdot 3$ & $45 \cdot 9$ & 17.8 & $45 \cdot 9$ & 41.8 & $15 \cdot 7$ \\
\hline Middle & 63.5 & $55 \cdot 7$ & 22.4 & 54.4 & $43 \cdot 2$ & 11.3 & $50 \cdot 1$ & 38.5 & 15.4 & 41.9 & $41 \cdot 2$ & $17 \cdot 1$ & $40 \cdot 2$ & 35.5 & $17 \cdot 6$ \\
\hline Rich & 57.7 & $48 \cdot 8$ & $20 \cdot 0$ & 44.5 & 35.0 & 11.0 & 47.9 & 38.6 & $11 \cdot 7$ & 38.6 & $37 \cdot 7$ & $17 \cdot 6$ & $36 \cdot 1$ & $27 \cdot 8$ & 13.4 \\
\hline Richest & $40 \cdot 2$ & $32 \cdot 7$ & 14.0 & 30.9 & $24 \cdot 1$ & 7.6 & 30.5 & $25 \cdot 7$ & $11 \cdot 1$ & $26 \cdot 4$ & $25 \cdot 8$ & 13.0 & $25 \cdot 7$ & 20.6 & $12 \cdot 1$ \\
\hline
\end{tabular}


Table 3 Average annual rate of reduction (AAAR) of prevalence of stunting, underweight and wasting by selected background characteristics of children under 5 years of age ( $n 28$ 941), Bangladesh, 1996 to 2011

\begin{tabular}{|c|c|c|c|c|c|c|c|c|c|c|c|c|c|c|c|}
\hline & \multicolumn{5}{|c|}{ Stunting } & \multicolumn{5}{|c|}{ Underweight } & \multicolumn{5}{|c|}{ Wasting } \\
\hline & $\begin{array}{c}\text { AARR }^{*} \\
(\%)\end{array}$ & $\begin{array}{c}\text { AARR } \dagger \\
(\%)\end{array}$ & $\begin{array}{c}\text { AARR } \neq \\
(\%)\end{array}$ & $\begin{array}{c}\text { AARRß } \\
(\%)\end{array}$ & $\begin{array}{c}\text { AARR\| } \\
(\%)\end{array}$ & $\begin{array}{c}\text { AARR }^{*} \\
(\%)\end{array}$ & $\begin{array}{c}\text { AARR } \dagger \\
(\%)\end{array}$ & $\begin{array}{c}\text { AARR } \ddagger \\
(\%)\end{array}$ & $\begin{array}{c}\text { AARRß } \\
(\%)\end{array}$ & $\begin{array}{c}\text { AARR\| } \\
(\%)\end{array}$ & $\begin{array}{c}\text { AARR }^{*} \\
(\%)\end{array}$ & $\begin{array}{c}\text { AARR } \dagger \\
(\%)\end{array}$ & $\begin{array}{c}\text { AARR } \ddagger \\
(\%)\end{array}$ & $\begin{array}{c}\text { AARRß } \\
(\%)\end{array}$ & $\begin{array}{c}\text { AARR\| } \\
(\%)\end{array}$ \\
\hline National level & 5.08 & 0.33 & $4 \cdot 88$ & 0.98 & $2 \cdot 84$ & $7 \cdot 04$ & -0.35 & $1 \cdot 19$ & $2 \cdot 72$ & $2 \cdot 69$ & $15 \cdot 60$ & $-4 \cdot 25$ & $-5 \cdot 62$ & $2 \cdot 62$ & $2 \cdot 47$ \\
\hline \multicolumn{16}{|l|}{ Sex of child } \\
\hline $\begin{array}{l}\text { Female } \\
\text { Male }\end{array}$ & 5.06 & 0.58 & 4.83 & 0.21 & $2 \cdot 70$ & $6 \cdot 68$ & 0.32 & 0.18 & $2 \cdot 18$ & $2 \cdot 38$ & $15 \cdot 51$ & -3.77 & $-6 \cdot 87$ & $2 \cdot 16$ & $\begin{array}{l}2.15 \\
2.75\end{array}$ \\
\hline \multicolumn{16}{|l|}{ Maternal education } \\
\hline No education & 3.72 & -0.02 & $4 \cdot 19$ & 0.12 & 2.02 & $5 \cdot 37$ & -0.61 & 2.44 & -0.94 & 1.59 & 13.53 & -3.00 & -4.94 & 1.87 & $2 \cdot 14$ \\
\hline Primary & 4.58 & $-0 \cdot 15$ & 2.74 & 0.85 & 2.02 & 5.87 & -0.70 & $-2 \cdot 31$ & $2 \cdot 16$ & 1.30 & 13.87 & $-5 \cdot 85$ & -9.30 & 1.27 & 0.41 \\
\hline Secondary or higher & 3.45 & $-2 \cdot 21$ & 3.96 & -0.26 & 1.27 & 7.50 & -4.04 & -0.85 & 4.09 & $1 \cdot 77$ & $19 \cdot 68$ & $-7 \cdot 77$ & -5.44 & 2.96 & 2.99 \\
\hline \multicolumn{16}{|l|}{ Maternal BMl $\left(\mathrm{kg} / \mathrm{m}^{2}\right)$} \\
\hline Underweight $(\mathrm{BMl}<18.5)$ & 4.23 & -0.94 & 5.38 & -1.28 & 1.89 & $5 \cdot 14$ & -1.31 & 1.05 & 0.64 & 1.41 & $12 \cdot 79$ & -4.62 & -5.45 & 3.00 & 1.71 \\
\hline Normal $(18.5 \leq \mathrm{BMI}<25.0)$ & 5.48 & 0.26 & 3.82 & 1.53 & 2.79 & $7 \cdot 29$ & -1.32 & -0.25 & 3.22 & 2.29 & $15 \cdot 81$ & $-6 \cdot 00$ & -8.39 & 2.08 & 1.35 \\
\hline Overweight $(\overline{B M I} \geq 25 \cdot 0)$ & $10 \cdot 25$ & 0.97 & 4.88 & -3.89 & 3.19 & $18 \cdot 16$ & 4.45 & 1.37 & -5.89 & 4.94 & 29.09 & $-5 \cdot 65$ & 1.67 & -5.49 & $6 \cdot 11$ \\
\hline \multicolumn{16}{|l|}{ Residence } \\
\hline Urban & 2.76 & -1.49 & $6 \cdot 11$ & -0.02 & 1.88 & 3.90 & -1.99 & 3.47 & 4.06 & 2.39 & 10.98 & $-5 \cdot 50$ & -1.73 & 0.88 & 1.35 \\
\hline Rural & 4.79 & 0.46 & 4.58 & $1 \cdot 15$ & 2.76 & $6 \cdot 83$ & $-0 \cdot 27$ & 0.60 & $2 \cdot 41$ & $2 \cdot 43$ & $15 \cdot 58$ & -3.97 & -6.55 & 2.92 & $2 \cdot 38$ \\
\hline \multicolumn{16}{|l|}{ Division } \\
\hline Barisal & 7.63 & -1.43 & 5.02 & 1.44 & 3.23 & 5.78 & 2.47 & -3.82 & 3.42 & 2.02 & 8.58 & 7.58 & $-23 \cdot 11$ & 4.59 & 0.19 \\
\hline Chittagong & 4.32 & $-0 \cdot 19$ & 4.76 & $2 \cdot 17$ & $2 \cdot 78$ & 8.48 & -1.86 & 2.97 & $2 \cdot 33$ & 3.05 & $20 \cdot 55$ & $-6 \cdot 29$ & -3.48 & $2 \cdot 50$ & 3.92 \\
\hline Dhaka & 5.39 & -0.59 & 5.55 & 0.21 & 2.68 & 7.05 & -0.92 & 1.63 & $2 \cdot 11$ & 2.51 & $13 \cdot 47$ & $-2 \cdot 24$ & $-5 \cdot 78$ & -0.15 & 1.61 \\
\hline Khulna & 5.68 & 2.64 & 4.44 & 0.87 & 3.43 & 9.50 & -0.66 & 0.67 & 3.94 & 3.44 & 19.58 & $-10 \cdot 19$ & -4.68 & 5.52 & 3.24 \\
\hline Rajshahi & 5.58 & 0.52 & 4.35 & 4.71 & 3.81 & $5 \cdot 87$ & 0.32 & -0.29 & $5 \cdot 25$ & 2.83 & 11.72 & -4.49 & -4.85 & 3.28 & 1.65 \\
\hline Sylhet & $2 \cdot 23$ & $3 \cdot 14$ & 5.96 & -2.96 & $2 \cdot 15$ & 4.56 & 1.73 & 3.51 & -1.83 & 2.02 & 15.94 & -3.37 & -5.86 & -0.37 & 1.98 \\
\hline \multicolumn{16}{|l|}{ Wealth quintile } \\
\hline Poorest & 1.79 & -0.20 & 4.37 & 0.11 & 1.53 & 3.35 & -0.82 & $3 \cdot 10$ & 0.00 & 1.43 & $12 \cdot 25$ & $-2 \cdot 59$ & -4.65 & 3.22 & $2 \cdot 28$ \\
\hline Poor & $6 \cdot 10$ & 0.57 & $2 \cdot 88$ & 2.07 & 2.93 & 8.57 & -0.98 & 0.65 & $2 \cdot 13$ & $2 \cdot 66$ & 13.69 & -2.66 & -5.05 & 2.83 & 2.48 \\
\hline Middle & 4.96 & 1.97 & 5.44 & 0.97 & 3.35 & 8.00 & 2.78 & $-2 \cdot 16$ & 3.40 & 3.07 & $20 \cdot 00$ & -7.74 & $-3 \cdot 20$ & -0.70 & $2 \cdot 72$ \\
\hline Rich & $8 \cdot 20$ & -1.79 & 6.50 & 1.53 & 3.69 & $10 \cdot 35$ & $-2 \cdot 40$ & 0.72 & $6 \cdot 84$ & 4.01 & 17.97 & $-1 \cdot 70$ & $-13 \cdot 34$ & 6.05 & 2.92 \\
\hline Richest & $8 \cdot 33$ & 0.33 & 4.39 & 0.58 & 3.46 & $9 \cdot 49$ & -1.58 & -0.07 & 5.05 & 3.32 & $18 \cdot 29$ & -9.61 & $-5 \cdot 14$ & 1.59 & 1.89 \\
\hline
\end{tabular}

AARR for the period 1996-1997 to 1999-2000.

TAARR for the period $1999-2000$ to 2004

¥AARR for the period 2004 to 2007.

|Overall AARR for the period 1996-1997 to 2011 
Table 4 Projected prevalence of stunting, underweight and wasting for 2015 by selected background characteristics of children under 5 years of age ( $n 28941$ ), Bangladesh

\begin{tabular}{|c|c|c|c|}
\hline & $\begin{array}{l}\text { Projected prevalence of stunting } \\
\text { for } 2015(\%)\end{array}$ & $\begin{array}{l}\text { Projected prevalence of underweight } \\
\text { for } 2015(\%)\end{array}$ & $\begin{array}{c}\text { Projected prevalence of wasting } \\
\text { for } 2015(\%)\end{array}$ \\
\hline National level & $36 \cdot 7$ & $32 \cdot 5$ & $14 \cdot 0$ \\
\hline \multicolumn{4}{|l|}{ Sex of child } \\
\hline Female & 37.6 & 34.7 & 13.9 \\
\hline Male & $35 \cdot 8$ & $30 \cdot 2$ & $14 \cdot 2$ \\
\hline \multicolumn{4}{|l|}{ Maternal education } \\
\hline No education & 47.0 & $45 \cdot 8$ & $16 \cdot 3$ \\
\hline Primary & $43 \cdot 2$ & $40 \cdot 0$ & $17 \cdot 7$ \\
\hline Secondary or higher & 31.9 & $25 \cdot 4$ & 11.5 \\
\hline \multicolumn{4}{|l|}{ Maternal BMI $\left(\mathrm{kg} / \mathrm{m}^{2}\right)$} \\
\hline Underweight (BMI <18.5) & 47.3 & $46 \cdot 9$ & $19 \cdot 2$ \\
\hline Normal $(18.5 \leq \mathrm{BMI}<25.0)$ & 34.7 & $29 \cdot 6$ & $13 \cdot 3$ \\
\hline Overweight $(\mathrm{BMI} \geq 25 \cdot 0)$ & $22 \cdot 2$ & $16 \cdot 2$ & $6 \cdot 9$ \\
\hline \multicolumn{4}{|l|}{ Residence } \\
\hline Urban & 33.7 & $25 \cdot 3$ & $13 \cdot 1$ \\
\hline Rural & $38 \cdot 0$ & 34.9 & 14.5 \\
\hline \multicolumn{4}{|l|}{ Division } \\
\hline Barisal & 38.9 & $36 \cdot 2$ & $14 \cdot 6$ \\
\hline Chittagong & $36 \cdot 7$ & $32 \cdot 9$ & 13.4 \\
\hline Dhaka & 38.9 & $32 \cdot 8$ & 14.5 \\
\hline Khulna & 29.2 & $25 \cdot 0$ & $12 \cdot 9$ \\
\hline Rajshahi & $28 \cdot 8$ & $30 \cdot 4$ & $15 \cdot 3$ \\
\hline Sylhet & $45 \cdot 7$ & 41.5 & $17 \cdot 0$ \\
\hline \multicolumn{4}{|l|}{ Wealth quintile } \\
\hline Poorest & $50 \cdot 3$ & 47.5 & $16 \cdot 3$ \\
\hline Poor & $40 \cdot 8$ & 37.5 & $14 \cdot 2$ \\
\hline Middle & $35 \cdot 0$ & $31 \cdot 3$ & $15 \cdot 7$ \\
\hline Rich & $31 \cdot 0$ & $23 \cdot 6$ & 11.9 \\
\hline Richest & $22 \cdot 3$ & $18 \cdot 0$ & $11 \cdot 2$ \\
\hline
\end{tabular}

Bangladesh $^{(15)}$. A possible reason could be the use of different data sets and time periods. In the UNICEF study the main data sources were DHS, Multiple Indicator Cluster Surveys and other national household surveys for around the period 1990-2008, whereas our data sets were five DHS rounds conducted during the period 1996-2011. The study by UNICEF also reported the AARR for prevalence of underweight in South Asia. The AARR reported for Bangladesh was greater than that for India, Nepal and Pakistan and lower than that for Afghanistan, Bhutan, Maldives and Sri Lanka.

Our results also show that despite the reduction of undernutrition observed in rural areas the prevalence remains higher in rural areas compared with urban areas, in line with previous studies ${ }^{(9,12)}$. This finding reinforces the need to prioritize nutrition intervention programmes to rural areas especially among the rural poor households. Regarding reduction of undernutrition by geographical area, our findings suggest that the situation in Khulna division and Rajshahi division is improving but that in Sylhet division is doing worse. A possible reason for the relatively poor performance of Sylhet division might be because it is an area with poor measles vaccine coverage compared with others in the country ${ }^{(3,25,26)}$. Studies have reported that children who receive measles vaccine are less likely to be malnourished ${ }^{(7,27)}$. In addition, appropriate child feeding practices according to the Infant and
Young Child Feeding standard is low in Sylhet division compared with other divisions in the country ${ }^{(3)}$. Moreover, the proportion of children consuming foods high in vitamin A is lowest in Sylhet division compared with other divisions ${ }^{(3,26)}$.

Our findings also indicate that the decline in the prevalence of undernutrition varies according to wealth status of the household. In the past 15 years, the proportion of underweight and wasted children has reduced greatly in the wealthiest quintile. Previous studies have shown that, on average, the prevalence of severe stunting was three times higher among children of the poorest households compared with children of wealthier households ${ }^{(28)}$. Research findings from Bangladesh also suggest that the likelihood of a child being malnourished decreases with the improvement of household wealth status ${ }^{(9,10)}$. More importantly, we forecast that in 2015 more than half of the children from the poorest quintile will be stunted. This finding indicates that poverty remains a major determinant for reduction of undernutrition at the household level. Undernutrition interventions, such as the Vulnerable Group Feeding and Food-for-Work programmes, have had significant impacts on reducing child malnutrition among the poorest quintile but our results show that further improvements are needed ${ }^{(29)}$.

Finally, our estimates of projected prevalence of underweight show that, if the present overall AARR continues to 
be observed in the future, Bangladesh is likely to achieve the MDG1C target of reducing the prevalence of underweight to $33 \%$ at the national level by 2015 . The projected estimate for stunting, however, is $36.7 \%$ for 2015 , which is still very high. Consequently, efforts should focus not only on reducing underweight but also on reducing stunting, which can lead to poor growth and other adverse health outcomes ${ }^{(30)}$.

\section{Acknowledgements}

Acknowledgments: The authors wish to thank MEASURE DHS for granting permission to use the BDHS data. Financial support: This research received no specific grant from any funding agency in the public, commercial or notfor-profit sectors. M.T.H is supported by an International Postgraduate Research Scholarship from the University of Queensland (\#43054112). Conflict of interest: None. Authorship: M.T.H. and A.A.M. conceived the study. M.T.H. performed data analysis and wrote the first draft. A. A.M. and R.J.S.M. contributed to data interpretation and preparation of the manuscript. G.M.W. edited and provided important intellectual feedback. Ethics of human subject participation: This study used publicly available secondary data sets from the BDHS conducted in 19961997, 1999-2000, 2004, 2007 and 2011. Ethical approval was not required.

\section{References}

1. World Health Organization (2012) World Health Statistics 2012. Geneva: WHO; available at http://www.who.int/gho/ publications/world_health_statistics/2012/en/

2. Shekar M, Heaver R \& Lee Y (2005) Repositioning Nutrition as Central to the Development Agenda: A Strategy for Large Scale Action. Washington, DC: The World Bank; available at http://web.worldbank.org/WBSITE/EXTERNAL/TOPICS/ EXTHEALTHNUTRITIONANDPOPULATION/EXTNUTRITION/ 0,,contentMDK:20787550 menuPK:282580 pagePK:64020865 $\sim$ piPK:149114 theSitePK:282575,00.html

3. National Institute of Population Research and Training, Mitra and Associates \& ICF International (2013) Bangladesh Demographic and Health Survey 2011. Dhaka and Calverton, MD: NIPORT, Mitra and Associates, and Macro International; available at http://www.measuredhs.com/pubs/pdf/FR265/ FR265.pdf

4. UNICEF (2013) Improving Child Nutrition: The Achievable Imperative for Global Progress. New York: UNICEF; available at http://www.unicef.org/publications/index_68661. html

5. Mohsena M, Mascie-Taylor CG \& Goto R (2010) Association between socio-economic status and childhood undernutrition in Bangladesh; a comparison of possession score and poverty index. Public Health Nutr 13, 1498-1504.

6. Jesmin A, Yamamoto SS, Malik AA et al. (2011) Prevalence and determinants of chronic malnutrition among preschool children: a cross-sectional study in Dhaka City, Bangladesh. $J$ Health Popul Nutr 29, 494-499.

7. Rahman A \& Chowdhury S (2007) Determinants of chronic malnutrition among preschool children in Bangladesh. J Biosoc Sci 39, 161-173.
8. Israt Rayhan M \& Khan MSH (2006) Factors causing malnutrition among under five children in Bangladesh. Pak J Nutr 5, 558-562.

9. Siddiqi MNA, Haque MN \& Goni MA (2011) Malnutrition of under-five children: evidence from Bangladesh. Asian J Med Sci 2, 113-119.

10. Das S, Hossain M \& Islam M (2008) Predictors of child chronic malnutrition in Bangladesh. Proc Pak Acad Sci 45, 137-155.

11. Helen Keller International (2006) Trends in Child Malnutrition, 1990 to 2005. Declining Rates at National Level Mask Inter-Regional and Socio-economic Differences. Dhaka: Helen Keller International; available at http://www. hki.org/research/NSP\%20Bulletin\%2019.pdf

12. Das S, Hossain MZ \& Nesa MK (2009) Levels and trends in child malnutrition in Bangladesh. Asia Pac Popul J 24, 51-78.

13. United Nations Development Programme (2014) Millennium Developmet Goals. http://www.undp.org/content/undp/en/ home/mdgoverview.html (accessed January 2014).

14. Ahmed T, Mahfuz M, Ireen S et al. (2012) Nutrition of children and women in Bangladesh: trends and directions for the future. J Health Popul Nutr 30, 1-11.

15. UNICEF (2009) Tracking Progress on Child and Maternal Nutrition. A Survival and Development Priority. New York: UNICEF; available at http://www.childinfo.org/files/Tracking Progress_on_Child_and_Maternal_Nutrition_EN.pdf

16. Chen LC, Chowdhury A \& Huffman SL (1980) Anthropometric assessment of energy-protein malnutrition and subsequent risk of mortality among preschool aged children. Am J Clin Nutr 33, 1836-1845.

17. World Health Organization (1995) Physical Status: The Use and Interpretation of Anthropometry, Report of a WHO Expert Committee. WHO Technical Report Series no. 854. Geneva: WHO; available at http://www.who.int/childgrowth/ publications/physical_status/en/

18. WHO Multicentre Growth Reference Study Group (2006) WHO Child Growth Standards: Length/Height-for-Age, Weightfor-Age, Weight-for-Length, Weight-for-Height and Body Mass Index-for Age: Methods and Development. WHO Technical Report Series no. 894. Geneva: WHO; available at http://www. who.int/childgrowth/standards/technical_report/en/

19. World Health Organization (2000) Obesity: Preventing and Managing the Global Epidemic: Report of a WHO Consultation. Geneva: WHO; available at http://apps.who.int/ iris/handle/10665/42330

20. UNICEF (2007) Technical Note: How to calculate Average Annual Rate of Reduction (AARR) of Underweight Prevalence. http://www.childinfo.org/files/Technical_Note_AARR.pdf (accessed May 2013).

21. Stevens GA, Finucane MM, Paciorek CJ et al. (2012) Trends in mild, moderate, and severe stunting and underweight, and progress towards MDG 1 in 141 developing countries: a systematic analysis of population representative data. Lancet 380, 824-834.

22. Fanzo JC \& Pronyk PM (2011) A review of global progress toward the Millennium Development Goal 1 hunger target. Food Nutr Bull 32, 144-158.

23. Black RE, Allen LH, Bhutta ZA et al. (2008) Maternal and child undernutrition: global and regional exposures and health consequences. Lancet 371, 243-260.

24. White H (2005) Maintaining Momentum to 2015?: An Impact Evaluation of Interventions to Improve Maternal and Child Health and Nutrition Outcomes in Bangladesh. Washington, DC: The World Bank; available at https:// openknowledge.worldbank.org/handle/10986/7372

25. National Institute of Population Research and Training, Mitra and Associates \& ORC Macro (2005) Bangladesh Demographic and Health Survey 2004. Dhaka and Calverton, MD: NIPORT, Mitra and Associates, and ORC Macro; available at http://www.measuredhs.com/pubs/pdf/FR165/ FR-BD04[FR165].pdf 
26. National Institue of Population Research and Training, Mitra and Associates \& ICF International (2009) Bangladesh Demographic and Health Survey 2007. Dhaka and Calverton, MD: NIPORT, Mitra and Associates, and Macro International; available at http://www.measuredhs.com/pubs/pdf/FR207/ FR207\%5BApril-10-2009\%5D.pdf

27. Ahmed AM, Ahmed T, Roy SK et al. (2012) Determinants of undernutrition in children under 2 years of age from rural Bangladesh. Indian Pediatr 49, 821-824.
28. Gwatkin DR, Rutstein S, Johnson K et al. (2007) SocioEconomic Differences in Health, Nutrition, and Population within Developing Countries: An Overview. Washington, DC: The World Bank; available at http://siteresources.world bank.org/INTPAH/Resources/IndicatorsOverview.pdf

29. Deolalikar AB (2005) Poverty and child malnutrition in Bangladesh. J Dev Soc 21, 55-90.

30. Dewey KG \& Begum K (2011) Long-term consequences of stunting in early life. Matern Child Nutr 7, Suppl. 3, 5-18. 